American Journal of Pharmaceutical Education 2020; 84 (5) Article 7682.

\title{
RESEARCH
}

\section{Global Health Learning Outcomes by Country Location and Duration for International Experiences}

\author{
David R. Steeb, PharmD, MPH, ${ }^{a}$ Monica L. Miller, PharmD, MS, ${ }^{b}$ Ellen M. Schellhase, PharmD, ${ }^{b}$ \\ Jodie V. Malhotra, PharmD, ${ }^{c}$ Jacqueline E. McLaughlin, PhD, ${ }^{a}$ Sarah A. Dascanio, PharmD, MPH, ${ }^{a}$ \\ Stuart T. Haines, PharmD ${ }^{\mathrm{d}}$ \\ ${ }^{a}$ University of North Carolina at Chapel Hill, UNC Eshelman School of Pharmacy, Chapel Hill, North Carolina \\ ${ }^{\mathrm{b}}$ Purdue University College of Pharmacy, Indianapolis, Indiana \\ ${ }^{\mathrm{c}}$ University of Colorado Skaggs School of Pharmacy and Pharmaceutical Sciences, Aurora, Colorado \\ ${ }^{\mathrm{d}}$ University of Mississippi School of Pharmacy, Jackson, Mississippi \\ Submitted May 10, 2019; accepted August 27, 2019; published May 2020.
}

Objective. To determine the impact of country income classification and experience duration on learning outcomes for student pharmacists participating in international advanced pharmacy practice experiences (APPEs).

Methods. A mixed-methods, longitudinal study evaluated 81 fourth-year student pharmacists participating in an international APPE through one of three US universities. A pre-post survey was administered to evaluate students' self-perceived growth across 13 competencies established by the Consortium of Universities for Global Health (CUGH). The survey included four additional openended questions. Student pharmacists were also invited to participate in a focus group. Paired and independent $t$ tests and multiple linear regression were conducted. Qualitative survey and focus group data underwent a two-cycle, open-coding process using conventional content analysis.

Results. Students who completed their APPE in a low- to middle-income country had greater growth in all CUGH competency statements compared to those who completed their APPE in a high-income country. Completing the APPE in a low- to middle-income country and prior travel for non-vacation purposes were significant predictors of student growth. Students who went to a low- to middle-income country demonstrated increased cultural sensitivity, more patient-centered care, and skill development, while students who went to a high-income country displayed increased knowledge regarding differences in health care system components, pharmacy practice, pharmacy education, and an appreciation for alternative patient care approaches.

Conclusion. Learning outcomes differed between students who completed an APPE in a high-income rather than a low- to middle-income country, with both types of locations providing valuable educational opportunities and professional and personal development.

Keywords: global health, global health education, experiential education, learning outcomes, assessment

\section{INTRODUCTION}

The pharmacist's role in global health is continuing to advance, and pharmacy schools are increasingly offering instructional and practice experiences related to global health in their curriculum. ${ }^{1}$ This growth has been supported by professional organizations as many have established special interest groups focused on global health education over the last decade. ${ }^{2,3}$ Pharmacists have

Corresponding Author: David R. Steeb, University of North Carolina at Chapel Hill, UNC Eshelman School of Pharmacy, 115I Beard Hall, 301 Pharmacy Ln., Chapel Hill, NC 275997574. Tel: 919-966-9789. Email: david_steeb@unc.edu the opportunity to make a significant contribution to national and international health agendas, including the United States' Healthy People 2020 plan and the United Nations' Sustainable Development Goals. ${ }^{4,5}$ As pharmacy education in the United States and other countries continues to emphasize the treatment of noncommunicable diseases and preventative medicine, pharmacists can be key contributors in increasing access to health care services as well as reducing morbidity and mortality worldwide.

International advanced pharmacy practice experience (APPEs) are the most common way in which schools have incorporated global health education into their curriculum. ${ }^{1}$ These experiences vary in duration from a few weeks 


\section{American Journal of Pharmaceutical Education 2020; 84 (5) Article 7682.}

to months, and placement occurs in both high-income and low- to middle-income countries. ${ }^{6}$ The most recent ACPE Standards, which incorporate the 2013 Center for the Advancement of Pharmacy Education (CAPE) outcomes, emphasize problem-solving, self-awareness, patient advocacy, and cultural competence, which are among the knowledge, skills, and attitudes that might be gained during international experiences. ${ }^{7,8}$ A growing body of literature has documented student learning while completing domestic APPEs in accordance to CAPE outcomes, but little is known regarding student learning while completing international APPEs. ${ }^{9}$ Given the diversity of the countries to which pharmacy schools send students, there needs to be better understanding as to how country location can influence learning outcomes and whether these outcomes align with accreditation standards.

Although medicine, dentistry, and nursing have developed global health competency frameworks, there are no pharmacy-specific constructs available on global health. ${ }^{10-12}$ In 2015 the Consortium of Universities for Global Health (CUGH) developed a "global citizen" global health competency framework for use across all health professions. Until now, however, this framework has not been used as an assessment tool for learning outcomes in any health profession. ${ }^{13}$ The CUGH competencies range from students being able to articulate barriers to health care in settings with limited resources to students exhibiting international values and communication skills. To date, most educational research across health professions on global health learning has come from low- to middle-income countries. There is a paucity of data regarding learning outcomes when students participate in practice experiences in developed countries (high-income countries). ${ }^{14,15}$ While the duration of the experience has a significant impact in undergraduate study abroad programs as it relates to students' personal and professional development, it is not known whether the duration of an international APPE influences learning outcomes for health professions students participating in global health experiences. ${ }^{16}$

The objective of this research was to evaluate selfperceived learning outcomes, defined as knowledge, skills, and attitudes, for student pharmacists who participated in an international APPE. Using the CUGH global health competency framework, we specifically examined the impact of country location and duration of the experience on learning outcomes.

\section{METHODS}

Final-year student pharmacists $(n=81)$ at the University of North Carolina at Chapel Hill (UNC), Purdue University, and the University of Colorado who had just completed an international APPE completed a retrospective pre-post Qualtrics survey instrument one week after returning to the United States. The survey assessed students' self-perceived ability to meet the CUGH competencies. The assessment instrument was created by placing the 13 CUGH global citizen global health competency statements into an online survey instrument with a five-point Likert scale ranging from $1=$ strongly disagree to $5=$ strongly agree. A composite score was calculated for each student using their responses to the 13 competency statements (the maximum possible score was 65).

A week prior to the survey on the CUGH competencies, students were sent four open-ended questions regarding the knowledge, skills, attitudes, and any other learning gained on the experience and instructed to reflect on these questions before submitting their responses. Students were also invited at that time to participate in an upcoming focus group to further explore their responses to the four questions and the survey on the CUGH competencies.

Twenty-two students agreed to participate in focus group interviews, including 18 students from the University of North Carolina at Chapel Hill and two each from Purdue University and the University of Colorado. Six virtual focus groups were held using ZOOM 4.1 (Zoom Video Communications, San Jose, CA) in which students were grouped by school and then by the income classification of the country in which they had completed their international APPE (ie, either a low- to middle-income country or a high-income country). Research team members led their respective focus groups using a jointly developed interview guide. Duration of the APPE varied by school, with those at the University of North Carolina at Chapel Hill lasting four weeks; University of Colorado, six weeks; and Purdue University, eight weeks. All student participants were asked about demographic information, including prior travel history, prior global health coursework, gender, and grade point average.

Qualitative analysis was conducted with MAXQDA software through a conventional content analysis approach for both the data collected through the open-ended questions as well as the focus group transcripts. A twocycle open (initial) coding process was used where the principal investigator coded all data while research team members were assigned to independently code particular questions. ${ }^{17}$ Face-to-face meetings resolved discrepancies to create a final codebook which was used to recode the data in the same process as the first coding cycle. During the coding process, each response was evaluated for depth of reflection using Kember's four-category hierarchy of critical reflection, which ranges from $1=$ habitual action to $4=$ critical reflection. ${ }^{18}$ Coding for the reflective depth of the response followed the same coding process 


\section{American Journal of Pharmaceutical Education 2020; 84 (5) Article 7682.}

above where the principal investigator and team members coded all data and then rectified any discrepancies through face-to-face meetings. Data were separated by the income classification of the country (high- or low-to-middle income) where the APPE had been completed and the student pharmacist's school. The technique of code mapping was applied to the final list of learning outcome codes from the survey and to focus group responses to identify and group codes into higher-level student learning themes across each group. ${ }^{17}$

All quantitative data analyses were conducted in SPSS for Windows, Version 23 (IBM, 2011). Continuous data are presented as mean (SD). Categorical data are presented as frequency (percent). Using recommendations from Carifio and Perla, parametric tests were used to analyze CUGH scores. ${ }^{19}$ Cronbach alpha was used to examine the reliability of the instrument. Independent $t$ tests were used to examine differences between independent groups (ie, students who completed an APPE in a low- to middle-income county vs students who completed an APPE in a high-income country), and paired $t$ tests were used to examine differences between paired data (eg, pre-experience score and post-experience score). Chi-square tests were used to analyze categorical variables for independent groups. Multiple linear regression was used to predict changes in student responses to the survey pre- and post-experience, as it was determined that this change was most indicative of the effects associated with completing a global APPE. The first regression model included all predictor variables. A more parsimonious model was derived using backward selection with a criteria of $p<.10$, which is the default criteria for retaining predictors during backward selection in many statistical packages. ${ }^{20,21}$
In other words, the parsimonious model was generated iteratively by removing variables with the highest $p$ values in a stepwise fashion until all variables in the model were $p<.10$. Parsimonious models explain the data with a minimum number of predictor variables. Statistical significance was established at $\alpha=.05$. The study design was based on a prior analysis by Steeb and colleagues regarding the assessment of global health learning outcomes for international experiences. $^{22}$ This study was reviewed and considered exempt by the institutional review board at each participating institution.

\section{RESULTS}

Eighty-one student pharmacists who participated in an international APPE completed the survey (100\% response rate). Forty-eight students were assigned to a low- to middleincome country, such as China, Ethiopia, Guatemala, India, Kenya, Malawi, Moldova, Tanzania, and Zambia, while 33 students were assigned to a high-income country, such as Australia, Canada, Japan, New Zealand, and the United Kingdom. There were no significant differences in key characteristics (eg, age, gender, grade point average [GPA]) between students who completed an APPE in a high-income country and those that completed an APPE in a low- to middle-income country (Table 1).

The mean CUGH competencies score for all participants increased from 43.5 (7.3) before the rotation to 53.4 (6.3) after the rotation $(p<.01)$. When analyzed based on the income classification of the rotation country, both groups demonstrated significant growth, with competency scores improving from 45.1 (8.1) to 50.9 (7.7) for students who completed their APPE in a high-income country $(p<.01)$ and from $42.4(6.5)$

Table 1. Demographics of Doctor of Pharmacy Students From Three Universities Completing International APPEs

\begin{tabular}{lccc}
\hline Characteristic & $\begin{array}{c}\text { Students Completing an } \\
\text { APPE in HIC (n=33) }\end{array}$ & $\begin{array}{c}\text { Students Completing an } \\
\text { APPE in LMIC (n=48) }\end{array}$ & $\begin{array}{c}\boldsymbol{p} \text { value } \\
\text { a }\end{array}$ \\
\hline Age, years, mean (SD) & $26.2(3.5)$ & $25.2(2.6)$ & .17 \\
Gender, female, No. (\%) & $26(78.8)$ & $36(75.0)$ & .69 \\
GPA, points, mean (SD) & $3.6(.3)$ & $3.6(.3)$ & .69 \\
Countries visited, mean (SD) & $4.2(3)$ & $4(3.1)$ & .87 \\
Prior international travel, yes, No. (\%) & $30(90.9)$ & $41(85.4)$ & .46 \\
$\quad$ Non-vacation, yes, No. (\%) & $15(50.0)$ & $29(70.7)$ & .08 \\
Prior time in low- to middle-income countries, & $2.2(2.1)$ & $2.8(3.6)$ & .36 \\
$\quad$ weeks, mean (SD) & $11(33.3)$ & $17(35.4)$ & .85 \\
Prior public or global health course, yes, No. (\%) & $14(42.4)$ & $25(52.1)$ & .38 \\
Institution, No. (\%) & $12(36.4)$ & $18(37.5)$ & $5(10.4)$ \\
$\quad$ University of North Carolina at Chapel Hill & $7(21.2)$ & & \\
$\quad$ Purdue University & &
\end{tabular}

Abbreviations: APPE $=$ advanced pharmacy practice experience, GPA= grade point average

Continuous variables represented as mean (SD); categorical variables represented as frequency (percent)

${ }^{a}$ Differences between groups examined by independent t-test for continuous variables and chi-square test for categorical variables

${ }^{\mathrm{b}}$ Non-vacation travel includes study abroad, mission trips, volunteering, family reasons, and other 


\section{American Journal of Pharmaceutical Education 2020; 84 (5) Article 7682.}

to 55.1 (4.7) for students who completed their APPE in a lowto middle-income country $(p<.01)$ (Table 2$)$. No difference in scores was found between the two groups on the retrospective pre-experience survey (42.4 [6.5] vs 45.1 [8.1], $p=.11$ ). However, students who completed their APPE in a low- to middle-income country scored significantly higher overall on the post-experience survey than did students who completed their APPE in a high-income country (55.1 [4.7] vs 50.9 [7.7], $p<.01)$. Growth as measured by the increase in scores from the pre-APPE to the post-APPE survey was also larger for the group completing APPEs in low- to middle-income countries when compared to the growth of students who completed APPEs in high-income countries (12.7 (6.3) vs 5.8 (6.0), $p<.01)$. The Cronbach alpha was .87 on the pre-experience survey and.91 on the post-experience survey, indicating high internal consistency for the instrument.

All variables were advanced to the first linear regression model (Table 3). Completing an APPE in a low- to middleincome country was the only predictor of change in a student pharmacist's total CUGH competencies score. When controlling for all other variables in the model, completing the APPE in a low- to middle-income country was associated with an increase of 7.5 points $(p<.01)$. The $\mathrm{R}^{2}$ for the full regression model was .37 . After removing variables using backward stepwise procedures with a criterion of $p<.10$, completing an international APPE remained significant, with a 7.6 increase in the composite CUGH competencies score when controlling for all other variables in the model $(p<.01)$ (Table 4). Prior travel for non-vacation reasons also had a significant effect in the refined model, with those students demonstrating less overall growth ( -3.8 points, $p=.03$ ) than students who had not previously traveled internationally for non-vacation reasons. The $\mathrm{R}^{2}$ for the refined regression model was .34. All models met the assumptions of linear regression, including lack of multicollinearity.

Code mapping of the survey and focus group data by country income classification (ie, high-income vs low-tomiddle income) led to identification of three main student learning themes for each income group. Coding inter-rater agreement for survey and focus group responses was $84 \%$ (346/412). Codes that appeared in a majority of responses for each income category are shown in Table 5, while representative student quotes of predominant learning outcomes are shown in Appendix 1. Reflection levels showed deeper reflection by students who completed an APPE in a low- to middle-income country compared to students who completed their APPE in a high-income country $(2.14$ vs $1.76, p<.01)$.

\section{Student Learning During Practice Experiences in Low- to Middle-Income Countries}

Over two-thirds of students who completed an APPE in a low- to middle-income country indicated having enhanced cultural awareness from both interactions in daily living and within the APPE setting. Interacting with health care providers and patients helped students learn about cultural influences on disease burden, health beliefs and values, and communication. Half of the students who completed their APPE in a low- to middle-income country developed an appreciation for culture beyond that of just an understanding, often noting how valuable it is to factor culture into patient interactions and treatment decisions. Some students appreciated certain cultural attitudes, including community support, patience, and positivity. A few students progressed further, developing cultural sensitivity and indicating that they would make an effort to consider their patient's culture during future interactions, with some stating that this would make them a more empathetic and better practitioner.

Among the students who completed their APPE in a lowto middle-income country, the care and management of patients was a prevalent student learning theme throughout most of their responses, focusing on issues like barriers to care, patient communication, and interprofessional collaboration. Issues regarding medication shortages, resource limitations, and social determinants of health required students to consider alternative treatment options. As students managed treatment options, they gained greater awareness of patient factors that can influence access to and quality of care, including medication cost, social support, transportation, and environmental influences on disease. Students indicated that providing care despite barriers enabled an appreciation for patient-centered care and interprofessional collaboration to address problems. Students also described gaining inspiration from and developing a newfound respect for the health care providers at their APPE sites as a result of the providers' commitment to patients and dedication to advancing pharmacy practice in their country.

The students who completed their APPE in a low- to middle-income country reported gaining more new skills, including communication, problem-solving, adaptability, and confidence. Resource limitations as well as cultural and language differences enhanced these students' ability to problem solve and adapt. Students indicated having improved communication skills, particularly cross-cultural and patient-related communication, which resulted from working through language and cultural barriers. As students navigated through these barriers, they indicated increased self-awareness and self-efficacy, which resulted in enhanced confidence. Students felt better prepared to take on responsibility, make patient care decisions, and thrive in unfamiliar situations after completing their international APPE.

\section{Student Learning During Practice Experiences in High-Income Countries}

Students who went to high-income countries to complete their APPE often described their learning from a health care 
American Journal of Pharmaceutical Education 2020; 84 (5) Article 7682.

Table 2. Student Pharmacists' Change in Response to Global Health Competency Statements Prior to and Following Completion of an International Advanced Pharmacy Practice Experience in a Low- to Middle-, or High-Income Country

\begin{tabular}{|c|c|c|c|c|}
\hline \multirow[b]{2}{*}{$\begin{array}{l}\text { CUGH Global Citizen Global Health } \\
\text { Competency }\end{array}$} & \multicolumn{2}{|c|}{ APPE in HIC } & \multicolumn{2}{|c|}{ APPE in LMIC } \\
\hline & $\begin{array}{c}\text { Pre-Survey } \\
(\mathrm{n}=33) \text { M (SD) }\end{array}$ & $\begin{array}{c}\text { Post-Survey } \\
(\mathrm{n}=33) \text { M (SD) }\end{array}$ & $\begin{array}{l}\text { Pre-Survey } \\
(\mathrm{n}=48) \text { M (SD) }\end{array}$ & $\begin{array}{c}\text { Post-Survey } \\
(\mathrm{n}=48) \text { M (SD) }\end{array}$ \\
\hline $\begin{array}{l}\text { 1a. Describe the major causes of morbidity and } \\
\text { mortality around the world, and how the risk } \\
\text { for disease varies with regions. }\end{array}$ & $3.1(1.1)$ & $3.6^{\mathrm{a}}(0.9)$ & $2.6(0.8)$ & $4.2^{\mathrm{b}}(0.5)$ \\
\hline $\begin{array}{l}\text { 1b. Describe major public health efforts to } \\
\text { reduce disparities in global health (such as } \\
\text { Millennium Development Goals and Global } \\
\text { Fund to Fight AIDS, TB, and Malaria). }\end{array}$ & $2.5(1.0)$ & $2.9(1.0)$ & $2.3(0.9)$ & $3.7^{\mathrm{b}}(0.9)$ \\
\hline $\begin{array}{l}\text { 2c. Describe how travel and trade contribute to } \\
\text { the spread of communicable and chronic } \\
\text { diseases. }\end{array}$ & $3.4(1.1)$ & $3.8(1.0)$ & $3.3(0.9)$ & $4.1^{\mathrm{b}}(0.6)$ \\
\hline $\begin{array}{l}\text { 3a. Describe how cultural context influences } \\
\text { perceptions of health and disease. }\end{array}$ & $3.4(1.1)$ & $4.0^{\mathrm{b}}(0.7)$ & $3.3(1.0)$ & $4.4^{\mathrm{b}}(0.5)$ \\
\hline $\begin{array}{l}\text { 3b. List major social and economic } \\
\text { determinants of health and their effects on } \\
\text { the access to and quality of health services } \\
\text { and on differences in morbidity and } \\
\text { mortality between and within countries. }\end{array}$ & $3.3(1.2)$ & $3.9^{\mathrm{b}}(0.9)$ & $3.3(0.9)$ & $4.3^{\mathrm{b}}(0.6)$ \\
\hline $\begin{array}{l}\text { 3c. Describe the relationship between access to } \\
\text { and quality of water, sanitation, food, and } \\
\text { air on individual and population health. }\end{array}$ & $3.6(0.9)$ & $3.9(0.9)$ & $3.6(0.9)$ & $4.3^{\mathrm{b}}(0.5)$ \\
\hline $\begin{array}{l}\text { 5d. Exhibit interprofessional values and } \\
\text { communication skills that demonstrate } \\
\text { respect for, and awareness of, the unique } \\
\text { cultures, values, roles/responsibilities and } \\
\text { expertise represented by other professionals } \\
\text { and groups that work in global health. }\end{array}$ & $3.9(0.8)$ & $4.3^{\mathrm{a}}(0.7)$ & $3.6(0.9)$ & $4.4^{\mathrm{b}}(0.5)$ \\
\hline $\begin{array}{l}\text { 5e. Acknowledge one's limitations in skills, } \\
\text { knowledge, and abilities. }\end{array}$ & $4.3(0.6)$ & $4.4(0.5)$ & $3.8(0.7)$ & $4.5^{\mathrm{b}}(0.5)$ \\
\hline $\begin{array}{l}\text { 6a. Demonstrate an understanding of and an } \\
\text { ability to resolve common ethical issues and } \\
\text { challenges that arise when working within } \\
\text { diverse economic, political, and cultural } \\
\text { contexts as well as when working with } \\
\text { vulnerable populations and in low-resource } \\
\text { settings to address global health issues. }\end{array}$ & $3.4(0.9)$ & $3.9(0.8)$ & $3.0(0.9)$ & $4.2^{\mathrm{b}}(0.7)$ \\
\hline $\begin{array}{l}\text { 7b. Articulate barriers to health and health care } \\
\text { in low-resource settings locally and } \\
\text { internationally. }\end{array}$ & $3.6(0.8)$ & $3.9(0.9)$ & $3.3(0.9)$ & $4.4^{\mathrm{b}}(0.5)$ \\
\hline $\begin{array}{l}\text { 8c. Demonstrate a basic understanding of the } \\
\text { relationships between health, human rights, } \\
\text { and global inequities. }\end{array}$ & $3.8(0.9)$ & $4.1(0.7)$ & $3.6(0.8)$ & $4.3^{\mathrm{b}}(0.5)$ \\
\hline 8e. Demonstrate a commitment to social & $4.0(0.8)$ & $4.2(0.8)$ & $3.7(0.7)$ & $4.4^{\mathrm{b}}(0.6)$ \\
\hline $\begin{array}{l}\text { responsibility. } \\
\text { 10a. Describe the roles and relationships of the } \\
\text { major entities influencing global health } \\
\text { and development. }\end{array}$ & $3.0(1.1)$ & $3.9^{\mathrm{b}}(0.8)$ & $2.8(0.8)$ & $4.0^{\mathrm{b}}(0.6)$ \\
\hline Total CUGH & $45.1(8.1)$ & $50.9^{\mathrm{b}}(7.7)$ & $42.4(6.6)$ & $55.1^{\mathrm{b}}(4.7)$ \\
\hline
\end{tabular}

Abbreviations: $\mathrm{M}=$ mean, $\mathrm{SD}=$ standard deviation, $\mathrm{CUGH}=$ Consortium of Universities for Global Health

${ }^{a} p$ value is $\leq .05$ and represents mean difference between the pre-score and post-score

${ }^{\mathrm{b}} p$ value is $\leq .01$ and represents mean difference between the pre-score and post-score 
Table 3. Predictive Pre-Post Composite Growth Change Model for the Consortium of Universities for Global Health Statements Instrument by Variable for Student Pharmacists who Completed an International Advanced Pharmacy Practice Experience Rotation $^{\mathrm{a}}$

\begin{tabular}{|c|c|c|c|c|}
\hline Variable & $\begin{array}{c}\text { Unstandardized } \\
\text { Coefficient (B) }\end{array}$ & $\begin{array}{c}\text { Standard } \\
\text { Error } \\
\text { (SE) }\end{array}$ & $\begin{array}{c}\text { Standardized } \\
\text { Beta }(\beta)\end{array}$ & $p$ value \\
\hline Intercept & -5.3 & 12.4 & & .67 \\
\hline Rotation income level [LMIC] & 7.5 & 1.5 & 0.5 & $<.01$ \\
\hline Age, years & 0.3 & 0.3 & 0.1 & .33 \\
\hline Gender [Female] & -0.6 & 1.7 & -0.0 & .74 \\
\hline GPA & 1.3 & 2.5 & 0.1 & .61 \\
\hline Countries visited, number & 0.5 & 0.3 & 0.2 & .09 \\
\hline Prior international travel [Yes] & -2.4 & 2.5 & -0.1 & .34 \\
\hline Prior travel for non-vacation ${ }^{\mathrm{b}}$ [Yes] & -3.8 & 1.9 & -0.3 & .05 \\
\hline Prior time in low-income countries, weeks & 0.1 & 0.3 & 0.0 & .74 \\
\hline Prior public health course [Yes] & 0.5 & 1.5 & 0.0 & .74 \\
\hline \multicolumn{5}{|c|}{ Institution [University of North Carolina at Chapel Hill] } \\
\hline Purdue University & 3.2 & 1.8 & 0.2 & .08 \\
\hline University of Colorado & -0.9 & 2.3 & -0.1 & .70 \\
\hline
\end{tabular}

Abbreviations: LMIC=Low- to Middle-Income Country, GPA= grade point average, CUGH=Consortium of Universities for Global Health; [Bracket] represents reference group for categorical variables

${ }^{a}$ Coefficient of determination for first linear regression model is $\mathrm{R}^{2}=.37$ which represents the proportion of variance in the dependent variable that is explained by the independent variable

${ }^{\mathrm{b}}$ Non-vacation travel includes study abroad, mission trips, volunteering, family reasons, and other

system perspective. Students indicated having increased knowledge about differences in health care delivery, payer and policy models, and technology that positively or negatively impacted patient care. Students mentioned that they had a greater appreciation for universal health care systems, with some indicating a desire to pursue a similar system in the United States. These comments correlated with students mentioning an appreciation for resource limitations that contribute to health care disparities here in the United States. Students more often referred to their experience as "eyeopening," which was usually in reference to the lack of electronic health record systems in other countries, including Australia and the United Kingdom.
Students who went to a high-income country location primarily mentioned codes related to pharmacy practice and education. They reflected on differences in roles and responsibilities of the pharmacist and pharmacy technician, with many describing increased responsibilities for pharmacy technicians and less autonomy for pharmacists compared to the United States. Students observed pharmacy practice differences in these countries that occurred because of many different factors, including laws, pharmaceutical manufacturing and compounding practices, and medication storage and dispensing policies.

Many students who completed their APPE in a highincome country reported learning about a new way to

Table 4. Refined Predictive Pre-Post Composite Growth Change Model for the Consortium of Universities for Global Health Statements Instrument by Variable for Student Pharmacists who Completed an International Advanced Pharmacy Practice Experience Rotation $^{\mathrm{a}}$

\begin{tabular}{lccrr}
\hline Variable & Unstandardized Coefficient & Standard Error & Standardized Beta & $\boldsymbol{p}$ Value \\
\hline Intercept & 4.6 & 1.6 & & $<.01$ \\
Rotation income level [LMIC] & 7.6 & 1.4 & .03 & $<.01$ \\
Countries visited, number $_{\text {Prior travel for non-vacation }}^{\text {b }}$ [Yes] & 0.4 & 1.7 & 0.2 & .09 \\
Purdue University [University of North $_{\quad}^{\quad \text { Carolina at Chapel Hill] }}$ & -3.8 & 1.4 & -0.3 & .03 \\
\hline
\end{tabular}

Abbreviations: LMIC=Low- to Middle-Income Country, GPA= grade point average, CUGH=Consortium of Universities for Global Health, [Bracket] represents reference group for categorical variables

${ }^{\mathrm{a}}$ Coefficient of determination for the refined regression model is $\mathrm{R}^{2}=.34$ which represents the proportion of variance in the dependent variable that is explained by the independent variable. Refined model derived using backward selection with a criterion of $p<.10$

${ }^{\mathrm{b}}$ Non-vacation travel includes study abroad, mission trips, volunteering, family reasons, and other 


\section{American Journal of Pharmaceutical Education 2020; 84 (5) Article 7682.}

Table 5. Prevalent Student Pharmacist Learning Outcomes by Country Location for International Advanced Pharmacy Practice Experience Rotations

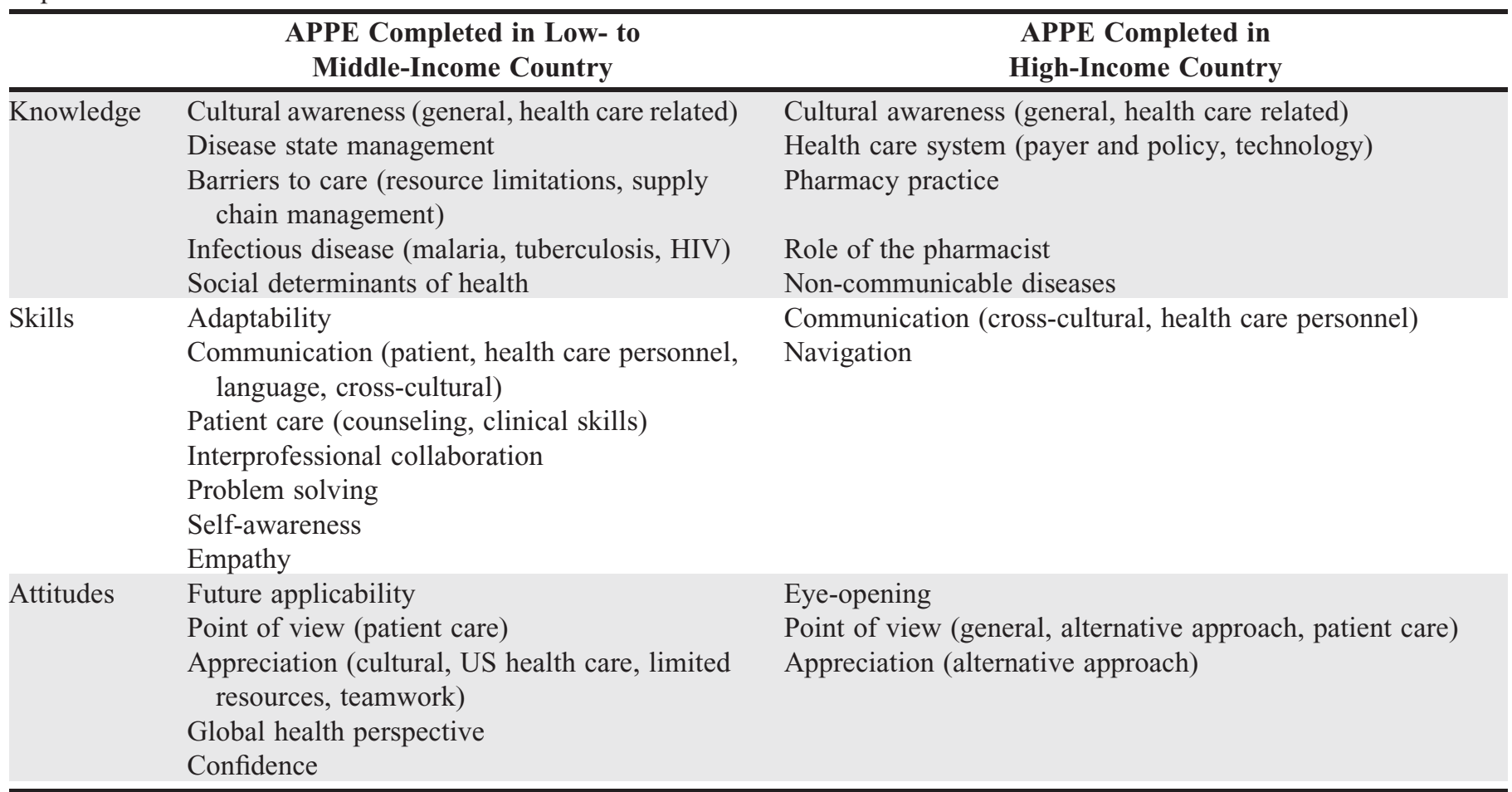

Abbreviation: APPE=Advanced Pharmacy Practice Experience

approach patient care. Some students referenced a new approach to the health care system structure, while others mentioned a new approach to transitions of care or patient communication. Over one-fourth of students mentioned a newfound appreciation for an alternative approach, often indicating a desire to implement it in their future practice. These approaches were often innovative methods for patient care that the student had not seen in the United States before but could see the value of implementing in their local setting. Despite each school having different APPE lengths as well as pre-departure training approaches, no qualitative trends were identified that correlated with the duration of the experience.

\section{DISCUSSION}

While student pharmacists who completed an APPE in a low- to middle-income country had significantly higher growth in CUGH competencies than students who completed an APPE in a high-income country, qualitative analysis revealed notable learning outcomes associated with the 2016 ACPE Standards across both groups. ${ }^{7}$ Subdomains for medication use systems management (2.2), populationbased care (2.4), and professionalism (4.4) were seen in the health care services of both high-income and low- to middleincome countries. Growth in the subdomains for patient- centered care (2.1), problem solving (3.1), patient advocacy (3.3), interprofessional collaboration (3.4), cultural sensitivity (3.5), communication (3.6), and self-awareness (4.1) were reported more often by students who completed their APPE in a low- to middle-income country. Growth in leadership (4.2) and innovation and entrepreneurship (4.3) were reported more often by students who completed their APPE in a high-income country. While some of these learning outcomes were more apparent in one group over the other, all learning outcomes were present in both groups. Global health experiences also support nearly all core entrustable professional activity (EPA) domains for graduates, with a particular focus on the roles of patient care provider, interprofessional team member, population health promoter, and self-developer. ${ }^{23}$ Mapping global health learning outcomes to ACPE Standards 2016, EPAs, and the CUGH framework can help programs develop pharmacyrelevant learning objectives and assessment strategies that can foster interprofessional collaboration.

There are two potential explanations for the divergence in learning outcomes and themes seen across country locations. First, relative differences in culture, patients, and resources between low- to middle-income countries and the student's past experiences is much greater, which may lead to greater reflection and perspective transformation. This is supported by Mezirow's theory of transformational 


\section{American Journal of Pharmaceutical Education 2020; 84 (5) Article 7682.}

learning, which states that transformative learning often begins with a disorienting dilemma, which could be caused by the significant cultural and patient care differences students experienced in low- to middle-income countries. ${ }^{24}$ Students appear to have used the skills of communication, problem-solving, and adaptability to determine the meaning of the differences they encountered. This process of exploration and critical reflection can stimulate greater cultural awareness as students go from the cognitive to the affective domain of learning, with some students wanting to incorporate cultural beliefs and values into their future patient interactions. ${ }^{25}$ While highincome APPEs can also provide a disorienting experience, the differences appear to be more subtle from student comments, and more research is needed to determine whether this produces a smaller transformational learning effect. There has been a growing recognition that the principles of global health can be applied to local environments. ${ }^{26}$ Therefore, there may be opportunities to deliver effective global health experiences in rural and inner-city communities in developed countries where observing the large resource differences could stimulate personal and professional transformation. ${ }^{26}$ Future research is needed to determine whether APPE learning outcomes may differ between low- and high-income neighborhoods in the United States and other developed countries.

Many of the CUGH competencies may be more relevant for low- to middle-income countries, which may explain why there was greater learning among these students. Programs that send students to developing countries may also be more likely to structure and label these practice experiences as "global health experiences" and emphasize certain CUGH competencies. This could help explain why completing an APPE in a low- to middle-income country was the most significant predictor of CUGH competency growth in the regression model. However, significant total growth in CUGH competencies also occurred in students completing their APPE in a high-income country, indicating that these experiences could be structured as global health experiences if APPE content is appropriately contextualized. Students in high-income countries grew the most within the areas of cultural awareness and social determinants of health ( $3 a$ and $3 b$ ), which may be attributed to the large, diverse populations associated with the urban locations of their APPE setting. Programs can help strengthen global health learning across all environments by helping students develop a "global to local" mindset as part of pre-departure training to enhance the students' ability to apply global health principles, regardless of setting. A "global to local" mindset reinforces the mantra of "think global, act local" in helping students better translate their global learning to local environments back home.
The learning outcome differences by country location were more patient-focused in low- to middle-income countries and more system-focused in high-income countries. Although APPEs in both the high-income and low- to middle-income countries involved patient care and engagement with the health care system, the majority of the pharmacy practice and health care system comments came from students who completed experiences in high-income locations. This may have been because of the relatively unstructured health care systems in low- to middle-income countries, which can make it difficult for students to compare to their experiences in the United States. Programs and preceptors for international APPEs should consider how to help students understand the linkages between patient care and health care systems, regardless of country location. One approach to consider could be the use of systems-level thinking to have students look at patient care problems and potential solutions from different perspectives. ${ }^{27}$ With pharmacy curricula emphasizing the prevention of disease and disease state management, students should recognize the global applicability of their training and the unique challenges that different health care systems face in addressing a common goal. Further research needs to assess which international APPE activities best lead to certain learning outcomes so these can be disseminated and translated across countries as best practices.

Regarding duration, the study abroad literature shows that longer international experiences have a greater impact than shorter experiences. ${ }^{16}$ Although Purdue's international APPE had the longest duration of the three schools, the regression model failed to show a significant difference in learning growth. There was positive growth on the CUGH competencies regardless of the APPE duration. There are several factors that may have impacted this finding, including differences in the curriculum, pre-departure training, and rotation-specific activities. With rotation lengths varying from four to eight weeks, the four-week difference may have been too small to produce a consequential effect. However, study abroad reports also indicate that six-week intensive experiences may be just as effective as longer, less-intensive experiences, suggesting that pre-departure training and APPE design may be more important factors in student learning than duration. ${ }^{16}$ Additional research is needed to determine if an international experience of one to two weeks, which is a common duration for many medical mission trips, would produce similar learning outcomes and growth.

There are some limitations to consider. The majority of the students in the focus groups came from one school, which may not have allowed for differences between students from different schools to be accurately assessed. Although UNC, Purdue, and Colorado were all chosen for 


\section{American Journal of Pharmaceutical Education 2020; 84 (5) Article 7682.}

this study because of their involvement in global health activities at a public, research-intensive institution, this study was unable to control for factors between the schools including APPE-specific learning activities and pre-departure training, and these may have impacted learning outcomes. The survey was administered following the international experience to mitigate response shift bias, but this may have resulted in recall bias and underreporting of some learning outcomes. Further, the pre-post design using self-reported measures could have led some students to overestimate their learning.

\section{CONCLUSION}

While international APPEs in high-income and low- to middle-income countries have different learning outcomes, both provide valuable global health learning, with greater growth seen among students participating in APPEs in lowto middle-income countries. Pharmacy programs can collaborate with other health professions using the CUGH competency framework to design transformative global health experiences that enable students to serve as patient care providers who are also global health practitioners.

\section{ACKNOWLEDGMENTS}

The authors wish to acknowledge Joe Xiaotong Yi, UNC Eshelman School of Pharmacy research assistant, for his assistance with quantitative data analysis.

\section{REFERENCES}

1. Prescott GM, Vu BN, Alsharif NZ, Prescott WA, Jr. Global health education in doctor of pharmacy programs in the United States. Am J Pharm Educ. 2017;81(2):28.

2. Kaffes I, Moser F, Pham M, Oetjen A, Fehling M. Global health education in Germany: an analysis of current capacity, needs and barriers. BMC Med Educ. 2016;16(1):304.

3. Pharmacy. ACoC. Practice and research networks. http://www. accp.com/about/prns.aspx. Accessed May 1, 2020.

4. Healthy People 2020. Washington, DC: U.S. Department of Health and Human Services, Office of Disease Prevention and Health Promotion. https://www.healthypeople.gov. Accessed May 1, 2020

5. United Nations. About the Sustainable Development Goals. https://www.un.org/sustainabledevelopment/sustainabledevelopment-goals/. Accessed May 1, 2020.

6. Steeb DR, Overman RA, Sleath BL, Joyner PU. Global experiential and didactic education opportunities at US colleges and schools of pharmacy. Am J Pharm Educ. 2016;80(1):7. 7. Medina MS, Plaza CM, Stowe CD, et al. Center for the Advancement of Pharmacy Education 2013 educational outcomes. Am J Pharm Educ. 2013;77(8):162.

8. Accreditation Council for Pharmacy Education. Accreditation standards and key elements for the professional program in pharmacy leading to the doctor of pharmacy degree standards. https://www.acpeaccredit.org/pdf/Standards2016FINAL.pdf. Accessed May 1, 2020.

9. Dennis VC, May DW, Kanmaz TJ, Reidt SL, Serres ML, Edwards HD. Pharmacy student learning during advanced pharmacy practice experiences in relation to the CAPE 2013 outcomes. Am J Pharm Educ. 2016;80(7):127. 10. Battat R, Seidman G, Chadi N, et al. Global health competencies and approaches in medical education: a literature review. BMC Med Educ. 2010;10(1):94.

11. Wilson L, Harper DC, Tami-Maury I, et al. Global health competencies for nurses in the Americas. J Prof Nurs. 2012;28(4):213-222. 12. Seymour B, Shick E, Chaffee BW, Benzian H. Going global: toward competency-based best practices for global health in dental education. J Dent Educ. 2017;81(6):707-715.

13. Jogerst K, Callender B, Adams V, et al. Identifying

interprofessional global health competencies for 21 st-century health professionals. Ann Glob Health. 2015;81(2):239-247.

14. Stys D, Hopman W, Carpenter J. What is the value of global health electives during medical school? Med Teach. 2013;35(3): 209-218.

15. Kulbok PA, Mitchell EM, Glick DF, Greiner D. International experiences in nursing education: a review of the literature. Int J Nurs Educ Scholarsh. 2012;9:1-21.

16. Dwyer MM. More is better: the impact of study abroad program duration. Frontiers: The Interdisciplinary Journal of Study Abroad. Fall 2004;10:151-163.

17. Saldaña J. The coding manual for qualitative researchers. In. The Coding Manual for Qualitative Researchers. Thousand Oaks, CA: Sage Publications Ltd:xi, 223--xi, 223.

18. Kember D, McKay J, Sinclair K, Wong FKY. A four-category scheme for coding and assessing the level of reflection in written work. Assess Eval High Educ. 2008;33(4):369-379.

19. Carifio J, Perla R. Resolving the 50-year debate around using and misusing Likert scales. Med Educ. 2008;42(12):1150-1152.

20. SAS. SAS/STAT(R) 9.2 User's Guide, Second Edition. https:// support.sas.com/documentation/cdl/en/statug/63033/HTML/default/ viewer.htm\#statug_reg_sect030.htm. Accessed May 1, 2020.

21. NCSS Statistical Software. Chapter 311: Stepwise Regression. https://ncss-wpengine.netdna-ssl.com/wp-content/themes/ncss/pdf/ Procedures/NCSS/Stepwise_Regression.pdf. Accessed May 1, 2020. 22. Steeb DR, Miller ML, Schellhase EM, et al. Global health learning outcomes in pharmacy students completing international advanced pharmacy practice experiences. Am J Pharm Educ. 2020;84(3):7586.

23. Haines ST, Pittenger AL, Stolte SK, et al. Core entrustable professional activities for new pharmacy graduates. Am J Pharm Educ. 2017;81(1):S2. 24. Mezirow J. Fostering critical reflection in adulthood: a guide to transformative and emancipatory learning. 1st ed. ed. San Francisco: Jossey-Bass Publishers; 1990.

25. Wells MI. Beyond cultural competence: a model for individual and institutional cultural development. J Community Health Nurs. 2000Winter;17(4):189-199.

26. Rowthorn V. Global/local: what does it mean for global health educators and how do we do it? Ann Glob Health. 2015;81(5):593-601. 27. Peters DH. The application of systems thinking in health: why use systems thinking? Health Res Policy Syst. 2014;12:51. 


\section{American Journal of Pharmaceutical Education 2020; 84 (5) Article 7682.}

Appendix 1. Quotes of Doctor of Pharmacy Students Representative of Global Health Learning Outcomes by Country Location

Learning Outcome

Low- to Middle- Income Countries

Cultural Sensitivity Progression

Patient-centered care

Skill development

High-Income Countries

Differences in Healthcare System

Components

Pharmacy Practice and Education

Alternative Patient Care Approaches

\section{Representative Student Quote}

"One of the things I think I've already started to take forward into my rotations and that I'll continue to take forward in my career is cultural competency and I don't think that just means, for me, diversity as far as racial groups or even like different parts of the [United States], but being able to work with different patients to be able to help them achieve their best health. . .every patient is different and being able to help them to find what works for them is my goal as a practitioner." - Focus Group Participant 7, Moldova

"Our conduct as healthcare professionals can affect the team... It is important not just to do the bare minimum but go further and instill the sense of responsibility into everyone else as a leader. At the end of the day, the patient care depends on each member and his/her role, and there are important distinctions in each member's function, which is why teamwork is critical." - Survey Participant 12, Kenya

"[The rotation] forces you to be adaptable. I think a big portion of that is. . . also being able to take those skills and bring them back to being adaptable in your next rotation in your new settings because whether we are in Malawi or in an ICU rotation there is things we are not going to know and things we have never faced before." - Focus Group Participant 2, Malawi

"I gained a lot of respect for countries that provide national healthcare because they view it as a human right rather than a privilege. The fact that I was able to see so many oncology patients and none of them were worried about how they were going to afford their medications was amazing. . .Being in London, despite all the animosity to NHS wait times, gave me more reasons as to why I should care less about my paycheck and more about the millions of Americans that cannot afford health insurance." - Survey Participant 3, United Kingdom

"I think one of the most important values I gained during my experience was observing the pharmacist's role in transitions of care and medication adherence in the Australian healthcare system. The diligence of the pharmacist in completing medication histories, communicating with primary care physicians, and compiling weekly pill boxes for their patients were important roles that stood out to me. As someone very interested in ambulatory care pharmacy and transitions of care, these practices were very valuable to see and have empowered me to work toward these changes in the [United States]." - Survey Participant 35, Australia

"I felt like the experience really opened my eyes to different types of medicine and helped me broaden my vision of pharmacy practice. . After learning about kampo dispensing in Japan, I understood that some patients are much more comfortable using the traditional medicine, and that the role of the pharmacist is to optimize the patient's health and well-being. . .In addition, some of the kampo formulations appear to have a lot of biochemical [mechanism of action] justifying its effects, which also made me realize that there is a lot of unexplored potential out there in traditional medicine that we just don't understand yet." - Survey Participant 5, Japan 